\title{
The hobbit - an unexpected deficiency
}

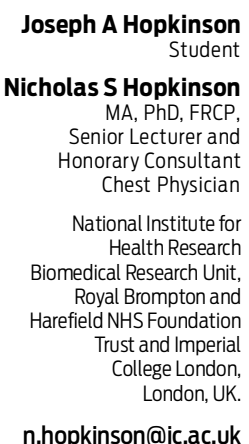

MJA 2013; 199: 805-806 doi: 10.5694/mjal3.10218 striking feature of fantasy literature has been the consistent victory of good characters over bad. While the consensus has been to attribute this to narrative conventions about morality and the necessary happiness of endings, we hypothesised that a major contribution to the defeat of evildoers in this context is their aversion to sunlight and their poor diet, which may lead to vitamin D deficiency and hence reduced martial prowess.

Vitamin D is a fat-soluble, secosteroid hormone, which in humans is largely synthesised in the skin when exposed to ultraviolet light, and is sometimes called "the sunshine vitamin". ${ }^{1}$ Vitamin D is also found in some foods, particularly oily fish and, in small amounts, in egg yolks, cheese, beef, liver and some mushrooms. It has a well described role in calcium metabolism, with deficiency resulting in rickets and osteomalacia. Vitamin D also has immune-modulating roles with potential effects on susceptibility to conditions ranging from multiple sclerosis to tuberculosis and accelerated lung function decline. ${ }^{2,3}$ Skeletal muscle weakness is known to be a feature of vitamin D deficiency although it has not been found to contribute to muscle dysfunction in chronic obstructive pulmonary disease (COPD) ${ }^{4}$ despite patients with COPD being noted for poor diet and reduced time spent outdoors. $^{5}$

A PubMed search performed on 29 July 2012 for studies that fulfilled both of the search terms "imaginary populations" and "vitamin D" returned no publications, suggesting that our hypothesis was untested, and leading to the work presented here.

\section{Methods}

We performed a pilot study using textual analysis to extract data relating to diurnal habits, dwelling, light exposure and diet from The hobbit by JRR Tolkien. Results are reported in an approximately consecutive narrative

\section{Abstract}

Objective: Vitamin $D$ has been proposed to have beneficial effects in a wide range of contexts. We investigate the hypothesis that vitamin $D$ deficiency, caused by both aversion to sunlight and unwholesome diet, could also be a significant contributor to the triumph of good over evil in fantasy literature.

Design: Data on the dietary habits, moral attributes and martial prowess of various inhabitants of Middle Earth were systematically extracted from J R R Tolkien's novel The hobbit.

Main outcome measures: Goodness and victoriousness of characters were scored with binary scales, and dietary intake and habitual sun exposure were used to calculate a vitamin D score (range, 0-4).

Results: The vitamin D score was significantly higher among the good and victorious characters (mean, 3.4; SD, 0.5 ) than the evil and defeated ones (mean, 0.2; SD, 0.4; $P<0.001$ ).

Conclusion: Further work is needed to see if these pilot results can be extrapolated to other fantastic situations and whether randomised intervention trials need to be imagined.

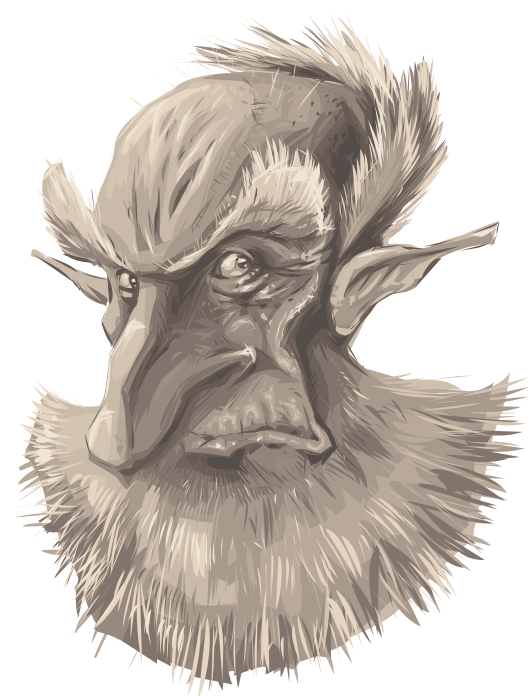

fashion. In addition, protagonists were identified as good or evil and victorious or defeated on binary scales by consensus. Sun exposure was scored from 3 (lots) to 0 (none at all) and diet was scored as 1 or 0 depending on whether any vitamin D-containing item was mentioned. These were summed to give a vitamin D score (range, 0-4), and this score was related to victoriousness by unpaired $t$ tests.

\section{Results}

Bilbo Baggins, a hobbit, lives in a hole in the ground but with windows, and when he is first encountered he is smoking his pipe in the sun overlooking his garden (it is worth noting [parenthetically] that smoking is itself associated with skeletal muscle dysfunction $\left.{ }^{6}\right)$. Dwarves and wizards smoke too, and the production of smoke rings is unfortunately glamourised. The hobbit diet is clearly varied as he is able to offer cake, tea, seed cake, ale, porter, red wine, raspberry jam, mince pies, cheese, pork pie, salad, cold chicken, pickles and apple tart to the dwarves who visit to engage him in the business of burglary. The dwarves also show evidence of a mixed diet and, importantly, although they "like the dark, the dark for dark business", they do spend much time above ground and have plenty of sun exposure during the initial pony ride in June that begins their trip to the Lonely Mountain.

Sun avoidance is a recurring theme among the evil characters. The trolls the party encounter shun the sunlight to avoid the petrification to which they eventually succumb and have been living on an exclusively mutton diet. They are certainly strong but undeniably stupid, and consuming jugs of "good drink" has further befuddled their wits.

Gollum, himself "as dark as darkness" lives in the dark, deep in the Misty Mountains. He does, however, eat fish, although the text describes 
Characteristics of inhabitants of Middle Earth

Vitamin

Inhabitants Good Victorious D score

$\begin{array}{llll}\text { Hobbits } & \text { Yes } & \text { Yes } & 4 \\ \text { Dwarves } & \text { Yes } & \text { Yes } & 3 \\ \text { Beorn } & \text { Yes } & \text { Yes } & 3 \\ \text { Men } & \text { Yes } & \text { Yes } & 4 \\ \text { High elves } & \text { Yes } & \text { Yes } & 4 \\ \text { Wood elves } & \text { Yes } & \text { Yes } & 2 \\ \text { Eagles } & \text { Yes } & \text { Yes } & 3 \\ \text { Smaug the } & \text { No } & \text { No } & 0 \\ \text { dragon } & & & \\ \text { Trolls } & \text { No } & \text { No } & 0 \\ \text { Goblins } & \text { No } & \text { No } & 0 \\ \text { Gollum } & \text { No } & \text { No } & 1\end{array}$

these only as "blind" and it is not clear whether they are of an oily kind and thus a potential source of vitamin D. He sometimes eats goblins, but they rarely come down to his lake, suggesting that fish play little part in the goblin diet. Interestingly, these occasional trips to catch fish are undertaken at the behest of the Great Goblin, leading one to speculate that his enhanced diet may have helped him to achieve his pre-eminent position within goblin society. In due course, the Great Goblin is replaced by the Son of the Great Goblin. While simple nepotism is a likely explanation, we are unable to exclude an epigenetic process whereby the son's fitness to rule has been influenced by parental vitamin $\mathrm{D}$ exposure.

Goblins' aversion to sunlight includes bringing a huge cloud of bats to accompany their army on the march. Like the Spartans at the Battle of Thermopylae, they expect to gain some advantage from fighting in the shade. ${ }^{7}$ However, despite their numbers, the goblins are defeated by their enemies. At the Battle of Five Armies, the strongest goblins are defeated by Beorn, a vegetarian who can assume the shape of a bear. His diet is largely cream and honey, but he spends much time outdoors.

Wood elves linger "in the twilight of our sun and moon", feasting merrily in clearings in the woods. They seem to be less potent than the high elves, perhaps because of their crepuscular habits, but their cave is described as "lighter and more wholesome" than goblin dwellings. Few details are given about their diet, but roast meat is involved, and butter and apples are brought to them by the river, as is wine.

Spiders dwell in the dark and seem to eat caught prey exclusively. The dragon Smaug comes out at night to eat people and particularly favours maidens, though he will also eat ponies and Lake-men.

The dietary and sun-exposure habits of the protagonists are shown in the Box. The mean vitamin D score was significantly higher among the victorious (mean, 3.4; SD, 0.5) than the non-victorious (mean, 0.2; SD, 0.4; $P<0.001)$. However, the absolute concordance between goodness and victoriousness precludes an assessment of this as an independent effect.

\section{Discussion}

Systematic textual analysis of The hobbit supports our initial hypothesis that the triumph of good over evil may be assisted to some extent by the poor diet and lack of sunlight experienced by the evil characters.

For the purpose of this study, we have not discriminated between creatures that can be considered, broadly speaking, to be mammalian and those that are not and whose physiology is more obscure. These include dragons, whose generation of fire has been discussed previously, ${ }^{8}$ as well as giant spiders and birds of unusual size.

Unfortunately, the principal purpose of the author of The hobbit was not to provide a systematic dietary history, so reporting bias is a possibility. In particular, there is an emphasis in the text on meat items similar to Homer's Odyssey, where feasting is a recurrent motif but where few references to salad are made.

More research would be needed to establish whether the results of the

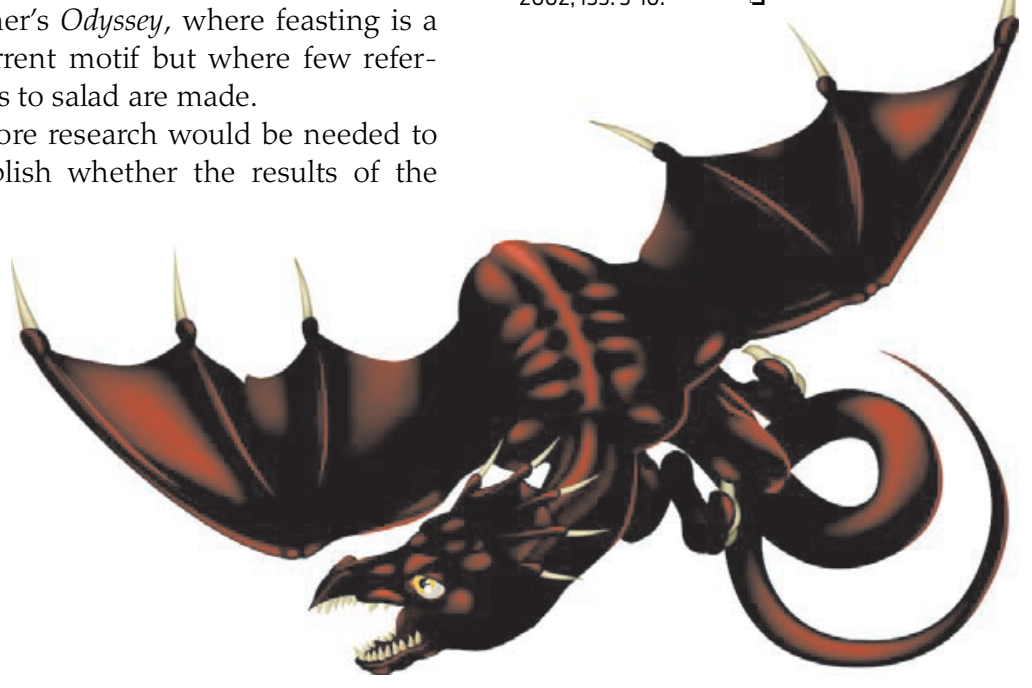

current pilot investigation are representative of the wider Tolkien corpus and indeed of fantastic literature in general, although this will need to be balanced against the problems of proportionality of effort. A further limitation is that the concordance of darkdwelling and evil make it more difficult to infer causation from the current data. Further reviews of the literature will need to focus on more morally ambiguous tales to elucidate this further, and the outcome of well constructed randomised controlled intervention studies may need to be imagined.

Acknowledgements: No specific funding was available for this work. Nicholas Hopkinson is supported by the National Institute for Health Research Biomedical Research Unit at Royal Brompton and Harefield NHS Foundation Trust and Imperial College London but would like to make it clear that he did this in his own time.

Competing interests: We declare that we have no conflicts of interest relating to this work, though Nicholas Hopkinson quite liked Game of thrones on the telly and Joseph Hopkinson has read all of the books.

Received 20 Feb 2013, accepted 7 Aug 2013.

1 Jackson AS, Hopkinson NS. Vitamin D in COPD - a pleiotropic micronutrient in a multisystem disease. Curr Respir Med Rev 2011; 7: 414-420.

2 Martineau AR, Wilkinson RJ, Wilkinson KA, et al. A single dose of vitamin D enhances immunity to mycobacteria. Am J Respir Crit Care Med 2007; 176: 208-213.

3 Barnard K, Colon-Emeric C. Extraskeletal effects of vitamin $D$ in older adults: cardiovascular disease, mortality, mood, and cognition. Am J Geriatr Pharmacother 2010; 8: 4-33.

4 Jackson AS, Shrikrishna D, Kelly JL, et al. Vitamin $\mathrm{D}$ and skeletal muscle strength and endurance in COPD. Eur Respir J 2013; 41: 309-316.

5 Donaldson GC, Wilkinson TM, Hurst JR, et al. Exacerbations and time spent outdoors in chronic obstructive pulmonary disease. Am J Respir Crit Care Med 2005; 171: 446-452.

6 Montes de Oca M, Loeb E, Torres SH, et al. Peripheral muscle alterations in non-COPD smokers. Chest 2008; 133: 13-18.

7 Herodotus. The histories. c 430 BCE; Book Seven, Section 226.

8 Georgy ST, Widdicombe JG. The pyrophysiology and sexuality of dragons. Respir Physiol Neurobiol 2002; 133: 3-10. $\square$ 